\title{
A EXPERIÊNCIA DO USO DE METILFENIDATO EM ADULTOS DIAGNOSTICADOS COM TDAH ${ }^{1}$
}

\author{
Luciana Vieira Caliman ${ }^{2}$ \\ Pedro Henrique Pirovani Rodrigues \\ Universidade Federal do Espírito Santo, Vitória-ES, Brasil
}

\begin{abstract}
RESUMO. O Transtorno de Déficit de Atenção e Hiperatividade (TDAH) é visto pelas autoridades médicas internacionais como um problema de ordem pública. O TDAH é envolto em questões que fazem urgir o debate acerca dos efeitos do diagnóstico e sua crescente difusão, entre as quais se destacam a recente expansão do diagnóstico para incluir o adulto e o vertiginoso aumento do consumo do metilfenidato. Como o fornecimento público do metilfenidato é contemplado pela Assistência Farmacêutica do Espírito Santo, a presente pesquisa tem por objetivo analisar os efeitos da Política Estadual de Assistência Farmacêutica referente ao TDAH na produção de subjetividade dos sujeitos que solicitam o metilfenidato. Busca-se abordar as experiências dos usuários no curso de seu tratamento medicamentoso. Foram realizadas entrevistas com solicitantes do metilfenidato maiores de 19 anos residentes em Vitória. Como resultado, percebeu-se que os efeitos advindos do diagnóstico e do uso do medicamento são mais diversos do que os comumente relatados e quase sempre experienciados de forma conflituosa e ambivalente. Ao mesmo tempo, tanto a Ritalina quanto o TDAH parecem funcionar como tecnologias subjetivas que, em sua relação com os sujeitos diagnosticados, transformam suas vidas em graus diversos, indicando a necessidade de acompanhamento dos seus efeitos.
\end{abstract}

Palavras-chave: Metilfenidato; TDAH; subjetividade.

\section{THE EXPERIENCE OF USING METHYLPHENIDATE IN ADULTS DIAGNOSED WITH ADHD}

\begin{abstract}
Attention Deficit Hyperactivity Disorder (ADHD) is seen by the international medical authorities as a matter of public order. ADHD is surrounded by issues that stress the importance of debating about the effects of the diagnosis and its growing dissemination. Among them, we highlight recent expansion of the diagnosis to include adults and the skyrocketing consumption of methylphenidate, the main drug indicated for its treatment. Given that Espirito Santo Pharmaceutical Care provides methylphenidate publicly, this article aims to analyze the usage experience of it by adults diagnosed with ADHD, as well as the impact of such a diagnosis in their lives. Therefore, interviews were conducted with methylphenidate users, who were over 19 years old and living in Vitoria. Diagnosis and methylphenidate usage effects found were much more diverse than is commonly reported, and they are often experienced as conflicting and ambivalent. At the same time, as Ritalin as ADHD seem to work as subjective technologies that transform diagnosed people lives to different degrees, pointing to the need to of monitoring its effects.
\end{abstract}

Keywords: Methylphenidate; ADHD; subjectivity.

\section{LA EXPERIENCIA DEL USO DE METILFENIDATO EN ADULTOS DIAGNOSTICADOS CON TDAH}

RESUMEN. El Trastorno por Déficit de Atención con Hiperactividad (TDAH) es visto por las autoridades médicas internacionales como un problema de orden público. EI TDAH está envuelto en asuntos que hacen urgir el debate sobre los efectos del diagnóstico y su creciente difusión. Entre ellos, cabe destacar la reciente expansión del

\footnotetext{
1 Apoio e financiamento: Fundação de Amparo à Pesquisa do Espírito Santo (FAPES).

2 Endereço para correspondência: Rua Petrolino Cesar de Moraes, 210, casa 25, Mata da Praia, CEP 29.066-230 Vitória-ES. E-mail: calimanluciana@gmail.com
} 
diagnóstico para incluir al adulto y al vertiginoso aumento del consumo del metilfenidato. Teniendo en cuenta que la provisión pública del metilfenidato es contemplada por la Atención Farmacéutica de Espírito Santo, esta investigación tiene como objetivo analizar los efectos de la Política Estatal de Atención Farmacéutica, dirigida para el TDAH, en la producción de subjetividad de los sujetos que solicitan el metilfenidato. Se busca abarcar las experiencias de los usuarios en el transcurso de su tratamiento medicamentoso. Fueron realizadas entrevistas con los solicitantes del metilfenidato con más de 19 años residentes en Vitória. Como resultado, se encontró que los efectos derivados del diagnóstico y del uso del medicamento son más distintos de los que comúnmente relatados, casi siempre experimentados de modo conflictivo y ambivalente. Al mismo tiempo, tanto la Ritalina como el TDAH parecen funcionar como tecnologías subjetivas que, en su relación con los sujetos diagnosticados, transforman sus vidas en diferentes grados, señalando para la necesidad de acompañamiento de sus efectos.

Palabras-clave: Metilfenidato, TDAH, subjetividad.

A partir da segunda metade do século $X X$ consumo de medicamentos aumentou significativamente, devido ao fortalecimento do paradigma biomédico, ao crescimento da indústria farmacêutica, à ampliação do acesso aos medicamentos e à intensificação dos processos de mercantilização da saúde e medicalização da sociedade (Poli Neto \& Caponi, 2007). O medicamento foi transformado na principal tecnologia médica moderna, num momento em que o sofrimento humano e as insatisfações cotidianas têm sido patologizados e medicalizados (Caliman, 2008; Conrad, 2007; Caponi, 2009). Assim, a discussão sobre medicamentos ultrapassa o campo biomédico, gerando também implicações sociais, econômicas, antropológicas e epidemiológicas (Ignácio \& Nardi, 2007; Itaborahy, 2009). Neste panorama, o Transtorno de Déficit de Atenção e Hiperatividade (TDAH) tem sido descrito como um dos diagnósticos que mais sustentam o processo atual de medicalização da vida, devido ao crescente consumo de metilfenidato (Ortega et al., 2010; ANVISA, 2010). Algumas das questões apontadas como problemáticas são: o número excessivo de diagnósticos em crianças e adultos, a patologização de questões que são de ordem educacional e a expansão do uso não médico do medicamento, do qual jovens e adultos fazem uso para melhorar a performance cognitiva ou para fins recreativos (Caliman, 2008).

No Espírito Santo, a dispensação pública de medicamentos essenciais e excepcionais tem sido realizada pelas Farmácias Cidadãs, dispositivos que compõem a Política Farmacêutica do Estado do Espírito Santo. Inauguradas em $2008 \mathrm{com}$ a finalidade de ampliar o acesso a medicamentos de alto custo e de serem elas um serviço de excelência em assistência farmacêutica, as farmácias cidadãs atendem, cada uma, a diferentes municípios para os quais é referência, sendo de investimento do tesouro do Estado os medicamentos que constam na lista estadual de dispensa à população (Caliman \& Domitrovic, no prelo). O cloridrato de metilfenidato, conhecido popularmente pelo nome comercial Ritalina $₫$ e tido como o principal medicamento indicado para o TDAH, é dispensado pelo Estado desde 2007, ano em que passou a integrar a Relação de Medicamentos Essenciais e Excepcionais REMEME (Caliman \& Domitrovic, no prelo). Embora esteja disponível no mercado brasileiro o medicamento de nome comercial Concerta $\AA$, cujo princípio ativo é o metilfenidato, não há dispensação pública deste no Espírito Santo.

Segundo Caliman e Domitrovic (no prelo), desde sua inclusão na REMEME a demanda de metilfenidato tem crescido enormemente. Tal crescimento vem acompanhado de um robusto aumento dos gastos com o metilfenidato pela Secretaria: em 2009 o gasto anual na compra do psicoestimulante totalizou $\mathrm{R} \$ 1.699 .254,20$, e dois anos depois o investimento para sua compra havia sofrido um aumento de $178 \%$, alcançando a cifra de $\mathrm{R} \$ 3.026 .167,80$ (Caliman $\&$ Domitrovic, no prelo).

Além do aumento no consumo do medicamento, o público-alvo contemplado foi expandido. Inicialmente dispensado apenas para crianças, em 2009 o adulto diagnosticado com TDAH também passou a ter o direito de solicitar o medicamento nas farmácias cidadãs. Embora a grande maioria da população atendida seja a infantil, constata-se um aumento crescente da procura pelo metilfenidato por indivíduos maiores de 19 anos, o que impõe novos desafios à análise do impacto das políticas de assistência farmacêutica voltadas para o TDAH (Caliman \& Domitrovic, no prelo).

Como sua expansão é recente, o diagnóstico adulto de TDAH tem sido pouco analisado e discutido e ainda é controverso. Ao mesmo 
tempo, a análise do uso do metilfenidato por essa população foi pouco explorada. Apesar do número exorbitante de livros, artigos e pesquisas publicados sobre o TDAH, a maior parte da literatura tem como foco o diagnóstico infantil. $\mathrm{O}$ diagnóstico do TDAH em adultos e seu tratamento medicamentoso trazem novos problemas, que devem ser mais bem discutidos e analisados. Neste sentido, através da realização de entrevistas, temos por objetivo analisar a experiência de uso do metilfenidato de adultos diagnosticados com TDAH que retiram o medicamento na Farmácia Cidadã Metropolitana, localizada no município de Cariacica.

Ao trazer a narrativa dos usuários de metilfenidato sobre seu tratamento e sobre o impacto do diagnóstico em suas vidas busca-se preencher uma lacuna nos estudos sobre o tema "Investigação da experiência dos sujeitos que vivem diretamente o impacto do diagnóstico e do medicamento". Acredita-se que para análise e acompanhamento das políticas públicas torna-se imprescindível considerar a experiência dos usuários desta política, além dos profissionais e gestores que a viabilizam. A partir da realização das entrevistas com os usuários de metilfenidato espera-se desenvolver subsídios para a criação de ferramentas analíticas, teóricas e de intervenção que auxiliem nos processos de implementação e avaliação das políticas e práticas da assistência farmacêutica direcionadas ao TDAH no Espírito Santo.

\section{MÉTODO}

Esta pesquisa foi desenvolvida em duas etapas. Na primeira, associada diretamente à Farmácia Cidadã Metropolitana, foram obtidos dados acerca da dispensação pública do metilfenidato no Estado do Espírito Santo, além de informações sobre os usuários desse medicamento que residem no município de Vitória.

Este primeiro momento se consolida a partir da pactuação com a Gerência de Assistência Farmacêutica do Espírito Santo (GEAF) e com a Coordenação da Farmácia Cidadã Metropolitana, que, alarmadas com o crescente uso do medicamento no Estado, apoiam a possibilidade de desenvolver um dispositivo de acompanhamento dos usuários do medicamento. O contato com os gestores foi fundamental para que o grupo de pesquisa se aproximasse da realidade do serviço prestado pela Farmácia Cidadã.

Através de consulta ao banco de dados digital da Farmácia Cidadã Metropolitana, foram obtidas informações referentes ao número de processos de solicitação do medicamento de outubro de 2008 até janeiro de 2012, e ao número de processos ativos de cada farmácia cidadã do Estado. Outros dados importantes que não constavam nessas listas - como residência, idade e telefone de contato dos usuários - foram obtidos através de consulta aos prontuários físicos. Desse modo, foram pesquisadas e registradas, em arquivo digital e físico, informações de 622 usuários de metilfenidato que, até janeiro de 2012, retiravam o medicamento na Farmácia Cidadã Metropolitana. Como esta unidade de serviço atende indivíduos de diversos municípios, para a realização das entrevistas tiveram preferência os usuários residentes em Vitória que fossem maiores de 19 anos. Um ou dois pesquisadores do grupo fizeram nove entrevistas, as quais foram gravadas em áudio e posteriormente transcritas. Esta pesquisa se realizou com a aprovação do Comitê de Ética em Pesquisa com Seres Humanos da Secretaria Estadual de Saúde do ES e em conformidade com a Resolução n 196/96 do CNS.

A segunda etapa da pesquisa foi dedicada à construção e realização das entrevistas, desde sua concepção metodológica até sua realização com os usuários do medicamento em questão. Para a realização das entrevistas distinguem-se dois sentidos de experiência não excludentes e inseparáveis: a experiência de vida e a experiência pré-refletida ou ontológica (Silva et al., 2010). O primeiro sentido refere-se ao uso comum do termo experiência, que inclui as emoções, a história de vida e as reflexões sobre as vivências dos sujeitos entrevistados. Já a experiência pré-refletida indica a dimensão de coemergência de si e de mundo, ou seja, ela não está dada de antemão e não é anterior ao processo da entrevista, mas se constitui na relação entre o sujeito entrevistado e seu entrevistador (Silva et al., 2010).

Assim, as entrevistas realizadas visaram não apenas evocar fatos vividos pelos sujeitos, relativos à experiência de ser diagnosticado com TDAH e fazer uso do metilfenidato (experiência de vida), mas também produzir deslocamentos e potencializar as falas e momentos de quebra dos 
automatismos referentes a estas vivências, possibilitando o acesso à experiência prérefletida.

Inicialmente se elaborou um roteiro para orientar as entrevistas, contendo eixos principais trabalhados pela pesquisa, a saber:

1. Queixa/situação ou demanda que levaram ao diagnóstico de TDAH e à prescrição de metilfenidato;

2. Experiência com o uso do medicamento;

3. Experiência do impacto do diagnóstico de TDAH.

Com a utilização destes eixos-guias, questões diversas foram sendo pontuadas na entrevista, com vista a abordar a experiência (de vida e pré-refletida) da medicação e o impacto do diagnóstico.

\section{RESULTADOS E DISCUSSÃO}

\section{Experiência com o diagnóstico}

De acordo com Hacking (2007), vivemos em um mundo de classificações e estas têm efeitos particulares quando se referem a comportamentos de pessoas. Pode-se dizer que na História sempre houve formas de classificação, mas foi somente nos últimos 200 anos de nossa história que o conhecimento científico tornou-se fundamental para a definição do que nós somos ou devemos ser e fazer. Hacking (2007) está interessado nas classificações das ciências humanas, da medicina à sociologia. $\mathrm{O}$ autor utiliza a expressão making up people para designar formas através das quais novas classificações científicas (das ciências humanas especialmente) fazem emergir novos seres, novas subjetividades, "tipos" de pessoas que não existiam antes de serem classificadas. Pode-se dizer que nos últimos trinta anos, no cenário científico as classificações biomédicas, baseadas nos saberes neurocientíficos, têm ganhado cada vez mais legitimidade na definição do que somos e de como devemos nos comportar (Rose, 2007). O TDAH é um diagnóstico biomédico, portanto, uma classificação. Assim, analisa-se o diagnóstico do TDAH como uma tecnologia subjetiva que interfere diretamente na produção da subjetividade dos indivíduos diagnosticados. Ele não simplesmente revela o que estava oculto a respeito da pessoa ou nomeia algo já presente de forma manifesta, mas também interfere na sua constituição (Hacking, 2007).

A literatura sociológica tem destacado os diversos efeitos - muitas vezes descritos como benéficos - do diagnóstico médico na vida das pessoas diagnosticadas. Para muitos, ter um diagnóstico acena para a possibilidade de curar ou ao menos tratar de uma situação geradora de sofrimento e mal-estar. Sobre isto assim se expressa uma entrevistada: "Que bom saber que tudo tem hoje uma solução, quando tem distúrbio, não é?". O diagnóstico oferece ainda uma resposta ou explicação para um comportamento que, por se desviar da norma, é tido como diferente e indesejado. Ele pode fazer com que uma queixa ou demanda seja acolhida pelo sistema de saúde e garantir acesso a outros direitos. Um dos sujeitos da pesquisa, por exemplo, atesta receber passe livre de ônibus por causa do diagnóstico de TDAH. Quando se trata de comportamentos vistos como desviantes ou socialmente indesejáveis, o diagnóstico pode produzir um efeito desculpabilizante naqueles que eram vistos e julgados como os únicos responsáveis pela conduta, agora explicada em termos médicos (Rose, 2007; Caliman, 2008; Ortega \& Zorzanelli, 2010).

$\mathrm{Na}$ literatura sobre o TDAH e nos sites da internet sobre o assunto é comum encontrarmos depoimentos de adultos diagnosticados destacando que a identificação do diagnóstico mudou suas vidas de forma radical. Quase sempre, esses depoimentos se dividem em dois grupos: o primeiro relata como o diagnóstico do TDAH propiciou a constituição de um sentimento de desculpabilização e alívio diante dos fracassos pessoais, antes vistos como decorrentes da vontade individual (ABDA, n.d). Nestes casos, aparentemente está em voga um processo de identificação com o diagnóstico que produz o sentimento de "ser um TDAH". Diferentemente, o segundo grupo, liderado por profissionais da saúde e da educação que combatem os processos de medicalização, expõe o desconforto individual e social relatado pelas crianças diagnosticadas com TDAH em seu processo de passarem a se ver e serem vistas como doentes mentais acometidos por um transtorno cerebral crônico e incurável (Fórum sobre medicalização da educação e da sociedade, n.d).

As entrevistas realizadas colocaram em evidência que entre estes dois polos diversos outros efeitos são produzidos na experiência de 
ser diagnosticado. Ao mesmo tempo, sentir-se desculpabilizado pelo diagnóstico não impedia que a mesma pessoa descrevesse o peso ou desconforto de se reconhecer ou ser reconhecido como portador de um transtorno mental, fosse ele visto como "leve" ou "grave". A relação estabelecida com o diagnóstico é quase sempre ambígua, mutante, e não se assemelha aos relatos encontrados na literatura. A dimensão experiencial parece portar, necessariamente, sentimentos ambíguos e paradoxais.

Percebe-se que os adultos têm o primeiro contato com o diagnóstico de TDAH antes mesmo de ir ao médico. $\mathrm{Na}$ internet, na televisão, nos livros sobre o assunto que já se tornaram populares, nas redes sociais, o acesso à informação sobre o TDAH tem sido comum. Quando o diagnóstico é confirmado pelo médico, a busca por informação não cessa e, em alguns casos, leva ao questionamento da avaliação médica. O processo de apropriação ativa do conhecimento médico sobre o diagnóstico não implica necessariamente na aceitação total da descrição e explicação biomédica do transtorno. Como indica Hacking (2007) ao descrever o que chamou de efeito de arco, ao ser classificado, o sujeito age sobre a classificação, reforçando-a ou alterando-a e ao mesmo tempo sendo transformado por ela. Mesmo quando havia uma forte adesão do sujeito ao diagnóstico, esta não era totalmente confortável, restando dúvidas e incertezas quanto aos limites da explicação médica.

De acordo com a descrição biomédica do TDAH, por exemplo, para receber o diagnóstico quando adulto é preciso que os sintomas do transtorno tenham sido manifestados também na infância. Este critério é desconsiderado ou transformado por quase todos os entrevistados, os quais, em suas lembranças, não se veem como crianças com TDAH. Inicialmente há um movimento de identificação com as características do diagnóstico: "Comecei mesmo a achar que tudo no passado era devido ao TDAH', mas tal identificação não permanece sem alterações. Uma entrevistada chegou a dizer que talvez seu caso não fosse "um caso muito verídico de TDAH", pois percebera ter sido uma situação ou momento específico de sua vida que deflagrou a demanda por mais foco e organização: "Sempre fui uma ótima aluna!"; no entanto o caráter situacional da queixa não impede que o diagnóstico seja legitimado e sentido como real pelos adultos diagnosticados. Outro entrevistado aponta a possibilidade de o diagnóstico ser adquirido e momentâneo. Neste caso, questiona-se o saber médico que o descreve como crônico e incurável. É interessante que a própria prática médica não considere todos os critérios necessários para fazer o diagnóstico, porquanto o TDAH em adultos é identificado mesmo na ausência do quadro infantil. Em um dos casos em que traços do TDAH infantil foram relatados, para o sujeito diagnosticado permaneceu ainda a sensação de que aconteceu "alguma coisa no meio do caminho [entre a adolescência e a vida adulta] que eu não sei contar" e que teria deflagrado o diagnóstico na vida adulta.

A crença na cronicidade do transtorno é por vezes sentida como um peso e, em alguns casos, surge atrelada à "possível" gravidade do problema. Sobre este aspecto, uma entrevistada afirma: "O que eu tenho é muito grave, [porque] não tem cura; é muito grave". O fato de considerar que o transtorno não tem cura e é muito grave faz com que o tratamento medicamentoso ocupe um lugar central na vida destes sujeitos, sendo vivenciado como uma necessidade da qual não se pode escapar. Interrogado sobre os momentos nos quais seria desejável não tomar o medicamento, um entrevistado declara que às vezes tem vontade de "se dar férias"; mas interroga: "mas não tem cura, 'né'?!'. A entrevistada (citada acima) que afirmava que seu caso era muito grave, também relatava: "sem o medicamento não posso ficar".

Por outro lado, as pessoas que descreviam o TDAH como um "pequeno transtorno" ou "apenas um déficit", diferenciando-o de doenças "realmente sérias", apontavam a possibilidade de usar medicamento apenas em determinadas circunstâncias. Ao ser percebido como situacional e pontual, o diagnóstico passa a interferir menos na construção do que Ortega (2003) chamou de bioidentidades. Nestes casos, se podemos falar que há uma identificação com o transtorno, ela não é completa, uma vez que o diagnóstico é transformado e apropriado pelos sujeitos de acordo com suas necessidades e pode ser abandonado: "passou, hoje posso caminhar sozinha".

Em quase todas as falas surge o efeito "desculpabilizante" do diagnóstico de TDAH. Uma entrevistada relatou que, na faculdade, se sentia "a burrinha da turma". Ao receber o diagnóstico este sentimento é aliviado. Em outro 
caso, no qual havia na família um relato de comparações entre as competências acadêmicas do jovem entrevistado e sua irmã, a explicação diagnóstica fez com que "as coisas lá em casa ficassem mais tranquilas... eu era a ovelha negra dos estudos". Para outro entrevistado este efeito de desculpabilização tornou-se um aspecto crucial. O sentimento de culpa pelos comportamentos indesejados, fracassos e impossibilidades esteve sempre presente em sua vida. As cobranças e autocobranças eram constantes:

quando eu descobri o transtorno eu falei assim “... então eu não sou incompetente, é um transtorno" ... e só isso já traz um alívio, que tira um pouco o peso da incompetência, de você não ser compatível com a sociedade, de você não ser capaz de produzir algo, quer dizer, não, eu tenho limites pra produzir, mas eu posso produzir (Fala de um entrevistado).

Impera em seu relato a lógica de uma sociedade culpabilizante e competitiva, que responsabiliza cada um por seus sucessos e fracassos (Ehrenberg, 2010). Nessa sociedade, ser autônomo significa ser independente, o único responsável pelo destino, que é individualmente traçado. Quando se tem o diagnóstico de TDAH, um pequeno desvio em tal lógica parece tornarse possível. O diagnóstico possibilita dizer que "não foi culpa sua", "você não é o responsável". Para algumas pessoas, o impacto deste sentimento pode ser tão marcante a ponto de dizer: "nasci de novo", quando recebe o diagnóstico de TDAH. Trajetórias profundamente marcadas pela culpabilização e cobrança social parecem ganhar aqui uma redenção, mesmo quando há um uso consciente da desculpa diagnóstica. Assume-se que, em certos momentos, o diagnóstico é usado como uma autodefesa "eu tenho que sair de algum lado, alguém 'tá' me cobrando uma coisa que eu não consegui.... eu digo que o DDA não deixa eu fazer"; mas um dilema ético passa a ser vivenciado: "O que sou eu e o que é o TDAH? Quando é culpa minha e quando meu comportamento resulta de uma incapacidade gerada pelo transtorno? Até que ponto tenho usado do diagnóstico para justificar meu comportamento?" Como vimos na fala acima, o entrevistado acredita que o diagnóstico explica que ele tem limites para produzir, mas que ele é capaz de produzir. Onde estaria a fronteira? Esta é uma pergunta que ressoa nas falas, uma busca continua: " $E$ isso que eu preciso saber".

Ao responsabilizar o cérebro por certos comportamentos, a explicação diagnóstica não possibilita uma completa desconstrução da lógica individualista embutida no culto à responsabilidade individual. Permanece o sentimento de que, em alguma esfera, o indivíduo continua sendo o único responsável pelo próprio destino. Este sentimento, quando ressignificado, pode levar a uma atitude de cuidado e atenção a si. O conhecimento sobre o transtorno parece exercer uma função importante no processo de voltar-se a si, impulsionado pela experiência de ser diagnosticado. Acredita-se que quanto mais se sabe sobre o transtorno, mais será possível contorná-lo, através de maior vigilância de si e de seus comportamentos, possibilitando a criação de estratégias para lidar com o problema.

A sensação de que "eu posso" contornar o problema, advindo do encontro com o diagnóstico, não necessariamente desconsidera a implicação dos outros na construção coletiva e compartilhada da vida. Neste caso, ao receber o diagnóstico o sujeito passa a se implicar na gestão de sua vida e esta gestão pode deixar de ser uma autogestão para tornar-se uma cogestão. Uma entrevistada, por exemplo, indagando sobre os limites da explicação diagnóstica, em um movimento de autorreflexão e autoanálise, lembra que tantos anos fora da escola dificultaram seu retorno à faculdade. Não é mais uma jovem de raciocínio rápido, não precisa ser melhor em tudo, algo que sempre exigiu de si mesma. Pensa agora que é importante ter consciência de seus limites e questiona a racionalidade que impõe a demanda de sucesso em todas as esferas da vida. $O$ TDAH e a experiência com o uso da Ritalina parecem ter ajudado na identificação de tais limites. O diagnóstico, neste caso, funcionou como um "sacolejo" que, unido a outros aspectos da vida, impulsionou um modo mais engajado de estar no mundo. Saber do diagnóstico, para outro entrevistado, propiciou-lhe

ter mais domínio, muito mais consciência da minha existência, daquilo que eu faço.... o fato de eu conseguir ter noção do que eu fazia e do que eu podia conquistar... hoje eu consigo ter metas através da consciência de ter o problema do DDA e de tomar Ritalina.... 
Não obstante, em outros casos, mantém-se fortemente a lógica individualizante, que continua buscando apenas no indivíduo as razões para as condutas indesejadas, mesmo na presença do diagnóstico. O "eu posso" convertese em "eu devo", sem considerar a dimensão coletiva que interfere na possibilidade ou não de fazer, de produzir, de ser competente.

\section{Experiência com o uso do medicamento}

As publicações médicas afirmam que 0 metilfenidato é imprescindível no tratamento de TDAH (Ortega et al., 2010). As informações difundidas sobre o medicamento em literatura científica e outros meios procuram destacar sua eficácia e seus efeitos esperados e colaterais no organismo. Assim como a discussão do TDAH é marcada pela polarização de pontos de vista acerca de sua existência, o uso do metilfenidato é amplamente discutido e também polemizado, ora indicado como o medicamento mais eficaz no tratamento do TDAH, ora descrito criticamente como a "droga da obediência". Por um lado se enfatiza que o metilfenidato promove melhora comportamental e possui baixa incidência de efeitos colaterais, e por outro, são destacados efeitos colaterais como insônia ou sonolência, alucinação, piora da cognição, hipertensão, parada cardíaca e o efeito designado por Zombie Like, descrito como ausência de pensamentos e sensações (Moysés, 2012). Sustentando ambas as posições, está a crença em uma ação objetiva do medicamento sobre um corpo, independentemente de seu caráter experiencial e social.

Não obstante, estudos em Antropologia Médica têm contribuído para a discussão das relações estabelecidas com 0 uso de psicofármacos e seus efeitos, os quais são experimentados em contextos reais de vida (Schlosser \& Ninnemann, 2012). Aponta-se aqui para a interação do medicamento com um corpo biológico (zoé), que é também dotado de vida sociopolítica (bios), sendo estes dois aspectos inseparáveis e em constante tensão (Ma, 2012). Estudos na área de farmacogenética apontam que, mesmo no que poderia ser definido como efeito "químico" do medicamento, é preciso considerar a singularidade de um organismo em interação constante com o meio (Ninnemann, 2012). É nesta direção que se critica a perspectiva biomédica que descontextualiza o uso do medicamento da experiência dos usuários (Schlosser \& Hoffer, 2012).
$\mathrm{Na}$ pesquisa realizada constata-se, com as entrevistas, o caráter variado das experiências com o uso da Ritalina. Os usuários não são vistos como meros recipientes do medicamento, uma vez que participam ativamente da definição de seus efeitos, os quais são construídos na relação estabelecida entre 0 usuário e 0 medicamento. Então, assim como o diagnóstico de TDAH é descrito como uma tecnologia subjetiva, a Ritalina é analisada como um artefato que, em relação com seus usuários, altera o sujeito e seu mundo. O medicamento é compreendido aqui não como um objeto de amplificação cognitiva, nem como um auxiliar externo às habilidades individuais, mas como um operador de transformações, seja das habilidades cognitivas e das tarefas, seja do próprio indivíduo e do seu mundo (Bruno, 2003).

O medicamento assume, assim, um estatuto cognitivo, constituindo a arquitetura cognitiva, pois participa ativamente da própria construção da cognição e atua sobre a atividade reflexiva dos sujeitos que o experimentam. O conceito de cognição aqui implicado baseia-se na compreensão de que os seres humanos são sistemas cognitivos constituídos por "uma topologia onde os limites entre o dentro e o fora, o interior e o exterior, não são firmemente traçados pela pele dos indivíduos e não constituem dimensões espaciais estáticas e definidas de antemão." (Bruno, 2003, p. 14) Desse modo, tanto os processos mentais (como a linguagem) quanto os artefatos técnicos nos constituem como sujeitos e integram nosso pensamento, participando do modo como agimos sobre o mundo e de como concebemos a nós mesmos.

Destacam-se, neste sentido, os relatos sobre a agressividade. Um dos entrevistados, fortemente impactado pelo diagnóstico e pelo uso do medicamento, traz questionamentos a respeito de quem ele se tornou após o uso do metilfenidato. Considera que o medicamento tem sido importante em sua vida e tem a sensação de ser um novo "eu" desde que começou a fazer uso do medicamento; mas relata, a respeito da agressividade (descrita, por vezes, como resultante do uso do medicamento ou da interação com ele), que "não gostaria de me tornar essa pessoa que eu 'to' me tornando (agressiva)". Por outro lado, não sabe distinguir se este é um efeito do medicamento ou se resulta de um processo que ele define como "reestruturação psicológica" ou das 
transformações que aconteceram ao longo de sua vida, pelas quais ele seria, em parte, responsável.

Em outra entrevista, a agressividade (descrita como resultante do uso do medicamento) é abordada como uma reação ou habilidade desejável, implicando na apropriação de atributos considerados importantes para o manejo da vida cotidiana. É relatado que o efeito (agressividade) do uso do medicamento a auxiliou na luta por direitos e no desenvolvimento da capacidade de questionar. Além disso, segundo relata a entrevistada, o efeito da Ritalina "parece que criou um novo mundo" de interesses e de possibilidades, inexistentes antes do encontro com 0 medicamento. Entende ela que poder concentrarse e tornar-se questionadora são capacidades que provêm do uso do medicamento, mas que, ao mesmo tempo, dependem dela para serem devidamente utilizadas.

Destaca-se o uso do medicamento para fins de produtividade acadêmica e de trabalho. Nestes casos, são relatados efeitos no estado de ânimo que retiram o sujeito da apatia - aqui a condição de "tônico do humor", atribuída ao medicamento em décadas passadas, conforme Dupanloup (2004), se faz presente. Neste sentido, fala-se em um "up" produzido pelo medicamento; mas os resultados ou impactos de tal efeito não são dados de antemão. Uma das entrevistadas, por exemplo, diz que com a Ritalina se consegue "render mais" para trabalhar e também para brigar. Outro entrevistado diz que, com a Ritalina, tem sua capacidade de planejamento aumentada, o que não corresponde à efetiva execução da tarefa.

Embora alguns entrevistados relatem que o medicamento influi no desempenho de atividades acadêmicas e de trabalho, a dimensão experiencial desse uso nos permite identificar aspectos que não são apontados pela literatura médica. A despeito de sentir que "rende muito mais" sob o efeito do medicamento, uma entrevistada não relata o mesmo efeito especificamente em suas aulas de inglês: "nem a Ritalina me segura lá, é horrível". Este relato aponta que o uso do metilfenidato para performance produtiva possui limites, embora seja indicado pela literatura médica e por alguns usuários. Tal efeito não pode ser descrito como dado a priori, independentemente da experiência de vida dos sujeitos que fazem uso do medicamento.
Embora nas entrevistas realizadas a dificuldade de concentração seja a principal queixa que leva ao uso do medicamento, questões diversas da vida dos entrevistados ganham novos contornos após o medicamento, resignificando a queixa inicial. Isto pode ser verificado na fala de uma entrevistada, a qual relata que se sente mais "segura" com 0 medicamento. Há, neste caso, a produção de uma experiência feita a partir do uso do medicamento que não está relacionada à queixa inicial de desatenção. De forma abrangente, o efeito destacado opera sobre sua relação com o mundo. Outro entrevistado relata que o medicamento o fez sentir-se, finalmente, um adulto, podendo exercer a função de pai, e não de um "amiguinho" dos filhos.

Uma entrevistada relata que sua relação com a Ritalina era a de "um casamento perfeito" até tornar-se "um amor proibido". A demanda pelo medicamento foi disparada quando, já aposentada, iniciou um novo curso de graduação. As exigências de concentração na universidade levaram à prescrição da Ritalina. $\mathrm{O}$ medicamento parecia ajudar muito nas aulas e em outros aspectos da vida, como dificuldades na fala (gagueira) e esquecimento. Além disso, conta que no início sentia um prazer enorme: "Eu senti primeiro um prazer, foi ótimo, descobri o Brasil"; mas o entusiasmo inicial foi interrompido. O "casamento perfeito" foi abalado quando o uso do medicamento começou a causar insônia, um problema presente há mais de vinte anos que havia sido superado e que não seria suportável em sua vida atual. Impõe-se uma escolha e uma decisão: "Sacrificar alguma coisa hoje pra não ter que voltar ao que estava antes". A partir de então, o medicamento torna-se um "amor proibido". Suas palavras são indícios de que a relação produzida com o efeito do medicamento é marcada afetivamente e que, embora ela relate experimentar efeitos desejáveis (a capacidade de desempenhar melhor atividades que requerem maior atenção) e um efeito indesejável (insônia), a relação estabelecida com o medicamento perpassa muitos aspectos de sua vida, participando da constituição de si e do mundo.

\section{CONSIDERAÇÕES FINAIS}

O diagnóstico de TDAH, assim como as outras classificações médicas, não causa 
sempre o mesmo impacto ou efeito na produção de subjetividade dos sujeitos diagnosticados. $O$ que ocorre é uma relação na qual classificação e classificados transformam-se mutuamente. Importa, então, perguntar qual a relação construída com o diagnóstico e quais os seus efeitos na vida dos sujeitos, os quais são sempre circunstanciais e mutáveis. Não podemos desconsiderar, por outro lado, que vivemos em uma sociedade na qual impera o culto à performance produtiva (Ehrenberg, 2010). Para muitos, é mais desejável ser considerado doente ou portador de um transtorno do que carregar a culpa advinda do processo de individualização e responsabilização dos nossos sucessos e fracassos (Costa, 2005; Rose, 2007).

É importante ressaltar que considerar a função "desculpabilizadora" dos biodiagnósticos no cenário atual não elimina a necessidade de problematizar o lugar privilegiado ocupado pelos diagnósticos e explicações médicas em nossas vidas. Quando as verdades e preceitos médicos se tornam os principais balizadores de nossas condutas, constituindo-se como tecnologias subjetivas, que formas de existência estamos produzindo? Quando tais verdades aliam-se a formas hierárquicas e especialistas de gerir o cuidado à saúde, prescrevendo e fortalecendo formas de vida endurecidas, modelos preestabelecidos de ser e de estar no mundo, como proceder para que um pouco mais do que o possível seja criado?

No que tange à experiência do uso do metilfenidato, vimos que a relação estabelecida entre o usuário e o medicamento não resulta do domínio do primeiro sobre o segundo ou o inverso (Bruno, 2003; Schlosser \& Hoffer, 2012). Trata-se de efeitos do encontro entre sujeito e medicamento não previamente estabelecidos, ainda que sob a égide de um diagnóstico ou de uma demanda específica. Afirma-se, então, o caráter indissociável da experiência dos sujeitos e da condição de efetividade da terapêutica medicamentosa. Por outro lado, se podemos falar dessa indissociabilidade e da necessidade de situar o uso do medicamento na história de vida de cada sujeito, também é preciso interrogar e problematizar a predominância que essa tecnologia subjetiva (medicamento) tem assumido no lidar com os problemas da vida, especialmente enquanto dispositivo de cuidado na saúde.

Sabemos que a conquista e a construção cotidiana do direito à saúde incluem o direito e acesso aos medicamentos. Não obstante, problematizamos as situações nas quais o direito à saúde tem sido simplificado e dilacerado, ao ser pensado como direito ao medicamento. Esta é uma questão que deve ser analisada e considerada pelas políticas públicas de Saúde e, no interior delas, pelas políticas de assistência farmacêutica. Importa, diferentemente, criar condições para a construção cotidiana de políticas que resistam às simplificações diagnósticas e medicamentosas.

$\mathrm{Na}$ medida em que o diagnóstico de TDAH e o metilfenidato são pensados como tecnologias subjetivas ou artefatos cognitivos que participam ativamente da produção dos sujeitos e de seus mundos, faz-se necessário atentar para mundos e sujeitos produzidos, visando transformar o direito ao medicamento em um direito ao cuidado ampliado à saúde dos sujeitos diagnosticados com TDAH.

\section{REFERÊNCIAS}

ABDA - Associação Brasileira de Déficit de Atenção e Hiperatividade (n.d). Depoimentos. Recuperado em 5 fevereiro, de 2013, de http://www.tdah.org.br/br/historias-reais.html.

ANVISA - Agência Nacional de Vigilância Sanitária (2010). SNGPC - Resultados 2009. Brasília, Recuperado em 26 janeiro, de 2012, de http://portal.anvisa.gov.br/wps/wcm/connect/19393 90047458e62976cd73fbc4c6735/SNGPC.pdf?MO $\mathrm{D}=\mathrm{AJP} P \mathrm{RES}$.

Barros, L. M. R. De (2010). Um Estudo Sobre A Noção De Experiência No Campo Da Cognição: $A$ Abordagem Enativa. Dissertação (Mestrado). Universidade Federal Fluminense, Instituto de Ciências Humanas e Filosofia, Departamento de Psicologia.

Bruno, F. (2003). Tecnologias Cognitivas e Espaços Do Pensamento. In: V. França; M. H. Weber; R. Paiva; L. Sovik. (Orgs.). Livro do XI Compós 2002: Estudos de Comunicação (pp.193-217). Sulina: Porto Alegre.

Caliman, L. V. (2008). O TDAH: Entre as Funções, Disfunções e Otimização da Atenção. Psicologia em Estudo, 13(3), 559-566.

Caliman, L. V., \& Domitrovic, N. (no prelo). Uma Análise da Dispensa Pública do Metilfenidato no Brasil: o Caso do Espírito Santo. Physis: Revista de Saúde Coletiva.

Caponi, S. (2009). Biopolítica e Medicalização dos Anormais. Physis Revista De Saúde Coletiva, 19(2), 529-549.

Conrad, P. (2007). The Medicalization of Society: on The Transformation of Human Conditions Into 
Treatable Disorders. Baltimore: The Johns Hopkins University Press.

Costa, J. F. (2005). O Vestígio e a Aura: Corpo e Consumismo na Moral do Espetáculo. Rio de Janeiro: Garamond.

Dupanloup, A. (2004). L'hyperactivité Infantile: Analyse Sociologique D'une Controverse SocioMedicale. Tese (Doutorado em Sciences Sociales). Université De Neuchâtel, Neuchâtel.

Ehrenberg, A. (2010). O Culto da Performance. (P. F. Bandassolli, Trad.). São Paulo: Ideias \& Letras.

Fórum sobre medicalização da educação e da sociedade (n.d). Manifesto do Fórum sobre medicalização da educação e da sociedade. Recuperado em 5 fevereiro, de 2013, de http://medicalizacao.org.br/manifesto-do-forumsobre-medicalizacao-da-educacao-e-dasociedade/.

Hacking, I. (2007). Kinds of People: Moving Targets. Proceedings of The British Academy, 151, 285318.

Ignácio, V. T. G., \& Nardi, H. C (2007). A Medicalização Como Estratégia Biopolítica: um Estudo Sobre o Consumo de Psicofármacos no Contexto de um Pequeno Município do Rio Grande do Sul. Psicologia \& Sociedade; 19(3): 88-95.

Itaborahy, C. (2009). A Ritalina no Brasil: Uma Década de Produção, Divulgação e Consumo. Dissertação (Mestrado em Medicina Social) Universidade do Estado do Rio de Janeiro, Instituto de Medicina Social, Rio de Janeiro.

Ma, Z. (2012). When Love Meets Drugs: Pharmaceuticalizing Ambivalence In Post-Socialist China. Culture, Medicine And Psychiatric, 36, 5177.

Moysés, M. A. A. (2012). Não às drogas da obediência. Metrópole, Campinas, p. 10-11, 5 ago. 2012. Entrevista concedida à Karina Fusco.

Ninnemann, K. M. (2012). Variability in The Efficacy of Psychopharmaceuticals: Contributions From Pharmacogenomics, Ethnopsychopharmacology, and Psychological And Psychiatric Anthropologies. Culture, Medicine and Psychiatric, 36, 10-25.
Ortega, F. J. G. (2003). Práticas de Ascese Corporal e Constituição de Bio-Identidades. Cadernos Saúde Coletiva, 11(1), 59-77.

Ortega, F. J. G., Barros, D., Caliman, L., Itaborahy, C., Junqueira, L., \& Ferreira, C. P. (2010). Ritalina no Brasil: Produções, Discursos e Práticas. Interface, 14(34), 499-510.

Ortega, F. J. G., \& Zorzanelli, R. T. (2010). Corpo em Evidência: a Ciência e a Redefinição do Humano. Rio de Janeiro: Civilização Brasileira.

Poli Neto, P., \& Caponi, S. N. C. (2007). A Medicalização da Beleza. Interface, 11(23), 569584.

Rose, N. (2007). The Politics of Life Itself: Biomedicine, Power, and Subjectivity In The Twenty-First Century. Princeton: Princeton University Press.

Schlosser, A. V., \& Hoffer, L. D. (2012). The Psychotropic Self/Imaginary: Subjectiviy And Psychopharmaceutical Use Among Heroin Users With Co-Occurring Mental Illness. Culture, Medicine and Psychiatric, 36, 26-50.

Schlosser, A. V., \& Ninnemann, K. (2012). Introducing To The Special Section: The Anthropology Of Psychopharmaceuticals: Cultural And Pharmacological Efficacies In Context. Culture, Medicine and Psychiatric, 36, 2-9.

Silva, A. E., Passos, E. H., Fernandes, C. V. A, Guia, F. R., Lima, F. R., Carvalho, J. F., Barros, L. M. R. \& Vasconcelos, C.S. (2010). Estratégias de Pesquisa no Estuda da Cognição: o Caso das Falsas Lembranças. Psicologia \& Sociedade, 22(1), 84-94.

Recebido em 11/09/2013 Aceito em 19/12/2013

Luciana Vieira Caliman: professora do Programa de Pós-Graduação em Psicologia Institucional e do Departamento de Psicologia da Universidade Federal do Espírito Santo.

Pedro Henrique Pirovani Rodrigues: aluno do curso de Psicologia da Universidade Federal do Espírito Santo, bolsista de Iniciação Científica da Fundação de Amparo à Pesquisa do Espírito Santo (FAPES). 